\title{
Heavy Metals Asetiologic Agents of Illness Due to Enviroment
}

\section{Giulio Tarro}

Foundation T. \& L. de Beaumont Bonelli for cancer research, Napoli, Italy

\begin{abstract}
After the first "white" book on "Health and Environment in Campania" (1977), there is a clear worsening of the environmental and health conditions of citizens. Illegal waste removal of toxic waste has led to an increase in tumor and malformation at birth (Campania, Land of Poison, 2012). Not always all the substances contained in illegal waste rubbish are known, but the presence of some of the moutlines the inevitabl ecarcinogenic effects [1].
\end{abstract}

Although there is no cancer record for the mapping of cancer cases in the area that can identify a correlation between the incidence of cancers and genetic/environmental cases (see mesothelioma), exposure to mutagenic carcinogenic substances (causing changes In the germ DNA) creates genetic damage through the malfunction of the gene switches, which is transmitted immediately to the next generation. Of all this, epigenetics is now being treated as a new key to tumor growth [2].

More recently, following the publication of Campania, Land of Poison, another paper was published in the Journal of Clinical and Experimental Cancer Research, on the incidence of Cancer in Campania, by improving the methodology of the previous study published in the same journal and extending the observation time until 2008, confirmed the significant increase in the number of breast tumor quadrantectomies and reported an increase in thosebetween 25 and 39 years and between 40 and 44 years, ie in pre-screening age [3].

At the end of 2013, a work by the Pascale Foundation on the mortality trend between 1988 and 2009 was published in the metropolitan areas of Naples and Caserta, where epidemiological data show a percentage increase in pulmonary cancer $68 \%$ for Caserta, more than $100 \%$ for Napoli compared to the "only" $41 \%$ increase for Italy. The regression analysis shows that the percentage increase in tumorsis $28.4 \%$ for men in Caserta and $47 \%$ in Naples, while for womenitis $32.7 \%$ and $40 \%$, respectively [4].

So, you can respond positively to the questions about the incidence of cancer and mortality in Campania, being higher than the Italian average. Of course, there is a scientific rigor and a map of polluted sites. We know of numerous carcinogens present with added dioxinrelated pollution, but the biggest danger is the pollution of the aquifers associated with illicit spills (Heavy metals) [5]. Most common Heavy metals involved in carcinogenesis: mercury, tin, lead, antimony, arsenic, thallum, cesium and gadiolinium [5]. Of course occupational exposure has Heavy metals in cigarettes smoking, cadmiumetc must be emphasized more.

After several interventions on the correlation between environmental pollution and cancer and the unsatisfactory answer to the question of the increased incidence of cancer related to the disposal of toxic waste, widely demonstrated by scientific publications, we must point out that the situation of the rest of Campania is no different from the one present in the land of fires (Naples and Caserta) [6].

Recently, the risk associated with exposure to asbestos has returned, and the Avellino Chemistry has been analyzed with the aim of

\section{Publication History:}

Received: September 11, 2017

Accepted: November 28, 2017

Published: November 30, 2017

\section{Keywords:}

Heavy metals, Enviroment, Carcinogenic, Contamination, Campania, Health

reclaiming it to prevent contamination by asbestos to other people. The scientific community was aware of the dangers of asbestos and both politicians and entrepreneurs were aware of their risks. In spite of all, the worker was considered to be a living being at the service of companies to which only his own account was important.

Geographic area most exposed to such risk factors are in Campania, region of Italy, Naples North and Caserta South as well as Avellino Provence because sites of transferring "special" wastes, that is toxic wastes, from regions of Italy more rich in industries as Piedmont, Lombardia, Veneto and Emilia Romagna [6].

For what it may concern the link between most common molecular genetic pathways vulnerable to the Heavy metals can be said that inhibit enzymes and molecules which provide antioxidant activity, by blocking the sulfhydryl groups (glutathione, metallothioneins, cysteine, alpha-lipoic acid) with a consequent increase of oxidative stress, alter the ionic homeostasis (calcium, sodium, potassium), mitochondrial function, in a selective manner by interfering with the Krebs cycle and with the methylation - Sulfooxidation circuit.

There are now extraordinary measures for preventing and combating the phenomenon of the abandonment of waste and the related swamps that impose a free screening on environmental illnesses for populations resident in areas affected over the past five years through local healthcare companies. In the technical and financial report, it should be noted that there is an initiative in line with the WHO directives which seek to know and cure diseases that fall under "environmental illnesses" on the medical and scientific level. Among other things, these important aspects of the law on poison land counteract the undoubted savings in the costs of managing the health care expenditure that will be burdened with the late care of cancerous and epidemiological diseases that delayed diagnosis then require treatment health-care costs that are more expensive than those prevented [7].

"Corresponding Author: Dr. Giulio Tarro, Foundation T. \& L. de Beaumont Bonelli for cancer research, Napoli, Italy, Tel: +393357758241 , Fax +390815750090 ; E-mail: giuliotarro@gmail.com

Citation: Tarro G (2017) Heavy Metals Asetiologic Agents of Illness Due to Enviroment. Int J Clin Med Microbiol 2: 124. doi: https://doi.org/10.15344/24564028/2017/124

Copyright: ( 2017 Tarro. This is an open-access article distributed under the terms of the Creative Commons Attribution License, which permits unrestricted use, distribution, and reproduction in any medium, provided the original author and source are credited. 
Citation: Tarro G (2017) Heavy Metals Asetiologic Agents of Illness Due to Enviroment. Int J Clin Med Microbiol 2: 124. doi: https://doi.org/10.15344/2456$4028 / 2017 / 124$

Page 2 of 2

The only possible solutions in 2014 are those already identified with foresight in the first white book of about 40 years ago based on the first prevention and reclamation after wards. In Texas, for example, since the land consolidation work began, malformations decreased by $40 \%$. Consequently, it could have a profound effect on remediation, reducing congenital malformations in only 4 years of $25 \%$, even reaching an economic savings of 11 millioneuros.

\section{Competing Interests}

The authors declares that they have no competing interests.

\section{References}

1. Giordano A, Tarro G (2012) Campania, terra di veleni. Denaro Libri, Luglio.

2. Kathryn S, Mazza A (2004) Triangle of death linked to waste crisis. The Lancet Oncology 5: 525-527.

3. Barba M, Mazza A, Guerriero C, Di Maio M, Romeo F, et al. (2011) Wasting lives: The effects of toxic waste exposive a health - The case of Campania, Sothern Italy. CancerBiol Ther 12: 106-111.

4. Crispo A, Barba M, Melvezzi M, Arpino G, Rosso T, et al (2013) Cancer mortality trends between 1988 and 2009 in the metropolitan area of Naples and Caserta, Southern Italy. Results from a join point analysis. Cancer Biol Ther 14: 1113-1122.

5. Tarro G F, Minguzzi R, Verzella F (2017) Toxic metals and autism. Theory Clin Pract Pediatr 1: 1

6. Marfè G, Di Stefano C (2016) The evidence of toxic wastes dumping in Campania, Italy. Crit Ben Oncol/Hematol 105: 84-91.

7. Tarro G, Altucci P (2016) Medicine and life perspectives. MEDIC 24: 51-57.

8. Tarro G (2015) Salute e ambiente in Campania una ricerca aggiornata nella "terra dei veleni". Politica Meridionalista 43: 18-20. 